\title{
SUPERIOR PATIENT SURVIVAL FOR CONTINUOUS AMBULATORY PERITONEAL DIALYSIS PATIENTS TREATED WITH A PERITONEAL DIALYSIS FLUID WITH NEUTRAL pH AND LOW GLUCOSE DEGRADATION PRODUCT CONCENTRATION (BALANCE)
}

\author{
Ho Yung Lee, ${ }^{1}$ Hyeong Cheon Park, ${ }^{1}$ Bo Jeung Seo, ${ }^{2}$ Jun Young Do, ${ }^{3}$ Sung Ro Yun, ${ }^{4}$ \\ Hyun Yong Song, ${ }^{4}$ Yeong Hoon Kim, ${ }^{5}$ Yong Lim Kim, ${ }^{6}$ Dae Joong Kim, ${ }^{7}$ \\ Yong Soo Kim, ${ }^{8}$ Curie Ahn, ${ }^{9}$ Moon Jae Kim, ${ }^{10}$ and Sug Kyun Shin ${ }^{11}$
}

\section{Department of Internal Medicine, College of Medicine Yonsei University, ${ }^{1}$ Seoul; Wallace Memorial Baptist Hospital, ${ }^{2}$ Pusan; Yeungnam University, ${ }^{3}$ Daegu; Konyang University, ${ }^{4}$ Daejeon; Inje University, ${ }^{5}$ Pusan; Kyungpook National University, ${ }^{6}$ Daegu; Sungkyunkwan University, ${ }^{7}$ Samsung Medical Center; \\ The Catholic University ${ }^{8}$; Seoul National University, ${ }^{9}$ Seoul; Inha University, ${ }^{10}$ Incheon; National Health Insurance Corporation Ilsan Hospital, ${ }^{11}$ Goyang, Korea}

- Background: In recent years, laboratory and clinical research has suggested the need for peritoneal dialysis fluids (PDFs) that are more biocompatible than the conventional PDFs commonly used today. Bioincompatibility of PDF has been attributed to low $\mathrm{pH}$, lactate, glucose, glucose degradation products (GDPs), and osmolality. PDFs with neutral $\mathrm{pH}$ and low GDPs are now available commercially. In vitro and early clinical studies suggest that these solutions are indeed more biocompatible but, as of now, there is no evidence that their use improves patient outcome.

- Methods: Using a dedicated database of over 2000 patients treated with PD in Korea, we were able to conduct a retrospective observational study comparing outcomes for incident continuous ambulatory PD patients treated with a standard, conventional, heat-sterilized PDF to the outcomes for patients treated with a novel, low GDP, neutral-pH PDF prepared in a dual-compartment, double-bag PD system (Balance; Fresenius Medical Care, St. Wendel, Germany). In an intention-to-treat analysis, patient and technique survival, peritonitis-free survival, and peritonitis rates were compared in 611 patients treated with Balance for up to 30 months and 551 patients with a standard PDF (stay - safe; Fresenius Medical (are) treated in the same era and with equivalent follow-up.

- Results: The patients were well matched for most relevant characteristics except older age distribution for the patients treated with the standard PDF. Patients treated with Balance had significantly superior survival compared to those treated with the standard PDF ( $74 \%$ vs $62 \%$ at 28 months, $p=0.0032$ ). In a multivariate Cox regression model includ-

Correspondence to: H.Y. Lee, Department of Internal Medicine, Yonsei University College of Medicine, CPO Box 8044, Seoul, Korea.

hyl@yumc.yonsei.ac.kr

Received 1 August 2004; accepted 13 0ctober 2004. ing age, diabetes, and gender, the survival advantage persisted (relative risk of death for Balance $0.75,95 \%$ confidence interval $0.56-0.99, p=0.0465)$. Modality technique survival was similar in Kaplan-Meier analysis for both PDFs. No differences were detected in peritonitis-free survival or in peritonitis rates between the two solutions.

- Conclusion: This study, for the first time, suggests that treatment with a novel biocompatible PDF with low GDP concentration and neutral $\mathrm{pH}$ confers a significant survival advantage. The exact mechanisms for such a survival advantage cannot be determined from this study. The usual criticisms of observational studies apply and the results reported here strongly warrant the undertaking of appropriately designed, randomized, controlled clinical trials.

Perit Dial Int 2005; 25:248-255 www.PDIConnect.com

KEY WORDS: Biocompatibility; neutral pH; glucose degradation products; patient survival.

The he evolution of the composition of peritoneal dialysis fluids (PDFs) reflects our progressive understanding of peritoneal physiology, solute kinetics, biocompatibility, and manufacturing processes. Normal saline was first used clinically as a PDF in the 1920s (1), and early formulations of PDF mimicked the physiological electrolytic composition of blood. Except for the use of various buffer bases throughout the years, the composition of PDFs remained essentially unchanged until the past decade. In recent years, the observation that peritoneal membrane performance and anatomy deteriorate over time exposed to PDFs resulted in a surge of activity in search of biocompatible solutions (2-5).

The recently published ADEMEX study (6) and commentaries arising after its publication (7) suggest that, 
to improve clinical outcomes for patients treated by continuous ambulatory peritoneal dialysis (CAPD), we have to look beyond peritoneal solute clearance to issues of volume management, preservation of residual renal function (RRF), and moderation of cardiovascular risk burden. For the latter, where chronic inflammation and oxidative stress are known risk factors (8), it is of interest to understand more fully the possible contribution of PDF bioincompatibility to these risk factors.

Recent research has generated a large body of in vitro and in vivo evidence associating glucose degradation products (GDPs), pH, osmolality, and lactate with functional and morphologic changes in peritoneal vessels, mesothelial cells, interstitium, and cells associated with host defense (9-15). The use of neutral-pH low-GPD solutions has been shown to improve peritoneal cell function and viability, both of which suggest prolongation of peritoneal membrane function and life, and better patient outcomes (16-18). However, until now there has been no clinical evidence that, indeed, patient outcomes are improved with the use of such PDFs.

The present retrospective observational study comparing outcomes among incident CAPD patients treated with either conventional PDFs or new pH-neutral lowGDP solutions is the first to show a survival advantage for patients treated with the new biocompatible PDFs.

\section{PATIENTS AND METHODS}

\section{PATIENTS}

Incident CAPD patients commencing treatment on or after 1 January 2002 and before 1 January 2004 with either standard PDF [stay · safe; Fresenius Medical Care (FMC), St. Wendel, Germany] or low-GDP neutral-pH PDF (Balance; FMC) were culled from a database of over 2000 patients treated with FMC PD products in 120 Korean dialysis centers. This start date was chosen because Balance was introduced commercially in Korea only in the latter half of 2001 and it was desirable to have patients treated with either solution from the same era. The dataset was further confined to adult patients (age $\geq 18$ years) and to those treated exclusively with CAPD (exclusion of automated PD patients).

The final dataset included 1162 patients treated in 83 dialysis centers. Of the 83 centers, 25 centers contributed only stay safe patients $(n=119)$ and 25 centers contributed only Balance patients $(n=201) ; 33$ centers contributed both stay safe $(n=432)$ and Balance patients $(n=410) ; 55$ centers had $\leq 10$ patients registered in the dataset (stay - safe 98 and Balance 105); 12 centers had $11-20$ (stay-safe 108 and Balance 73); 6 cen- ters had 21 - 30 (stay - safe 85 and Balance 75), 5 centers had 31 - 50 (stay-safe 62 and Balance 125), and 5 centers each contributed in excess of 50 patients (stay - safe 198 and Balance 233). These patient numbers do not necessarily reflect the total activity or experience of each center since the dataset includes only those patients being treated with a product supplied by FMC.

Of the 1162 patients included in the analysis, 611 patients were initiated and maintained on Balance, 376 were initiated and maintained on stay - safe, and a further 175 commenced treatment with stay - safe and subsequently were converted to Balance. None of these patients received simultaneous treatment with other PD solutions such as polyglucose or amino acid. The database was "closed" for analysis on 31 May 2004. The primary analysis was conducted on an intent-to-treat (ITT) basis. Thus, recorded events were ascribed to the first treatment received by the patient (stay - safe or Balance), irrespective of a switch from stay - safe to Balance.

Data recorded included unique patient identifiers, patient sex and age, primary renal diagnosis, date of enrolment, date of discharge (including death and dropout for any reason, including transfer to hemodialysis), reason for dropout, and cause of death. Because the database was created specifically to monitor patients treated using FMC products, patients converted to a competitor's product were classified as dropout on the date the patient was converted to another product. In addition, all peritonitis episodes occurring in this patient cohort were recorded as the date of onset of the episode. The dataset does not record laboratory data, clearance values, or peritoneal transporter status.

\section{PERITONEAL DIALYSIS TREATMENT}

Prescription and delivery of CAPD treatment, including the choice of PD solution (stay - safe or Balance), were at the discretion of the patients' treating physicians. Likewise, decisions to discontinue CAPD, to convert to hemodialysis, or to change the PD solution for a competitor's product were taken by the treating physician. The dataset does not record data indicating the reason for the prescribers' choices.

The standard PDF, stay ·safe, is a heat-sterilized PD fluid presented in a single compartment, double-bag system manufactured with the PVC-free foil Biofine and with disc-and-pin connectology as previously described (19). The low-GDP neutral-pH PDF, Balance, uses the same foil and connectology and is prepared in a dualchambered, double bag where a welded seam separates the glucose and electrolyte component at low pH (2.8 3.1) from the buffer component at alkaline $\mathrm{pH}$ during 
sterilization. By rupturing the seal dividing the compartments immediately prior to use, complete mixing of the two solutions is achieved virtually instantaneously. The chemical composition of the two solutions, including concentrations of common GDPs, is shown in Table 1.

\section{STATISTICAL ANALYSIS}

Statistical analysis was performed using SPSS, version 11.5 (SPSS Inc., Chicago, Illinois, USA). The unpaired Student's t-test was used to compare continuous normally distributed data; the chi-square test was used for comparison of categorical variables. Patient, technique, and peritonitis-free survivals for the two PD solutions were analyzed and compared using the Kaplan-Meier method and tested by log rank statistic. The Cox proportional hazards model was used to adjust for significant covariates, including the PDF used in treatment, patient age (continuous variable), patient sex (female vs male), and diabetic status (yes vs no). In the multivariate model, covariates were entered using the forward conditional method. In the analysis of patient survival, censored events included recovery of renal function, renal transplantation, and dropout to hemodialysis or to a competitor product. In the analysis of technique survival, the measured events included conversion to hemodialysis and transfer to a competitor product; all other events were censored. All statistics were two-tailed and statis-

TABLE 1

Comparison of the Chemical Composition of Two Peritoneal Dialysis Fluids (PDFs)

\begin{tabular}{lcc}
\hline & ${\text { stay } \text { safe }^{\mathrm{a}}}$ & Balance $^{\mathrm{a}, \mathrm{b}}$ \\
\hline Sodium $(\mathrm{mmol} / \mathrm{L})$ & 134 & 134 \\
Calcium $(\mathrm{mmol} / \mathrm{L})$ & 1.75 & 1.75 \\
Magnesium $(\mathrm{mmol} / \mathrm{L})$ & 0.5 & 0.5 \\
Chloride $(\mathrm{mmol} / \mathrm{L})$ & 103.5 & 101.5 \\
Lactate $(\mathrm{mmol} / \mathrm{L})$ & 35 & 35 \\
Bicarbonate $(\mathrm{mmol} / \mathrm{L})$ & 0 & 2 \\
$\mathrm{pH}$ & 5.5 & 7 \\
Glucose $($ anhydrous $)(\mathrm{g} / \mathrm{L})^{\mathrm{c}}$ & $15-42.5$ & $15-42.5$ \\
3-deoxyglucosone $(\mu \mathrm{mol} / \mathrm{L})^{\mathrm{c}}$ & $172-324$ & $42-60$ \\
${\text { Methylglyoxal }(\mu \mathrm{mol} / \mathrm{L})^{\mathrm{c}}}^{\mathrm{c}}$ & $6-10$ & $<1^{\mathrm{d}}$ \\
Acetaldehyde $(\mu \mathrm{mol} / \mathrm{L})^{\mathrm{c}}$ & $152-182$ & $<2^{\mathrm{d}}$ \\
Formaldehyde $(\mu \mathrm{mol} / \mathrm{L})^{\mathrm{c}}$ & $7-13$ & $<3^{\mathrm{d}}$
\end{tabular}

a Manufactured by Fresenius Medical Care, St. Wendel, Germany.

${ }^{\mathrm{b}}$ After mixing.

c The lower value in the range refers to $1.5 \%$ dextrose PDF and the higher value to $4.25 \%$ dextrose PDF.

d Below detectable limit. tical significance was defined by an alpha value less than 0.05 .

\section{RESULTS}

\section{CHARACTERISTICS OF PATIENTS AT ENROLMENT}

Table 2 lists the main characteristics of the patients allocated to the treatment PDFs on the ITT basis. For the recorded parameters, the two groups of patients (stay-safe and Balance) were well matched except for a significantly older age for patients treated with stay · safe (average difference +1.6 years, $p=0.049$ ). The proportion of patients treated with stay safe who were older than 60 years also exceeded that for patients treated by Balance ( $47 \%$ vs $39 \%$ respectively) but this was not statistically significant $\left(\chi^{2}=0.623, p=0.419\right)$. Sex distribution and distribution by cause of renal failure were similar for the groups (Table 2).

\section{PATIENT SWITCH FROM STAY·SAFE TO BALANCE}

The number of patients that switched from stay - safe to Balance was 175 . The mean interval from start of treatment to PDF switch was $9.5 \pm 6.1$ months. There was no difference in sex distribution or in rate of diabetes be-

\section{TABLE 2}

Main Characteristics of the Patients Treated by Two Peritoneal Dialysis Fluids Allocated on the Basis of Intent-to-Treat

\begin{tabular}{|c|c|c|c|}
\hline & $\begin{array}{c}\text { Balance }^{\mathrm{a}} \\
(n=611)\end{array}$ & $\begin{array}{l}{\text { stay } \cdot \text { safe }^{\mathrm{a}}}^{(n=551)}\end{array}$ & $p$ Value $^{\mathrm{b}}$ \\
\hline \multicolumn{4}{|l|}{ Year incidence } \\
\hline 2002 & $232(38 \%)$ & $324(59 \%)$ & \multirow[t]{2}{*}{$<0.0001$} \\
\hline 2003 & $379(62 \%)$ & $337(41 \%)$ & \\
\hline \multicolumn{4}{|l|}{ Sex } \\
\hline Female & $282(46 \%)$ & $240(44 \%)$ & \multirow[t]{2}{*}{0.066} \\
\hline Male & $329(54 \%)$ & $311(56 \%)$ & \\
\hline Age, mean (years) & $55.38 \pm 13.4$ & $56.97 \pm 13.9$ & 0.049 \\
\hline \multicolumn{4}{|c|}{ Age (category) } \\
\hline$\leq 60$ & 372 (61\%) & $294(53 \%)$ & \multirow[t]{2}{*}{0.419} \\
\hline$>60$ & $239(39 \%)$ & $257(47 \%)$ & \\
\hline \multicolumn{4}{|l|}{ Diabetic status } \\
\hline Nondiabetic & $302(49 \%)$ & $252(46 \%)$ & \multirow[t]{2}{*}{0.685} \\
\hline Diabetic & $309(51 \%)$ & $299(54 \%)$ & \\
\hline
\end{tabular}

a Manufactured by Fresenius Medical Care, St. Wendel, Germany.

${ }^{\mathrm{b}} p$ Values compare patients treated with stay safe with those treated with Balance. Proportions tested by chi-square and means by Student's t-test. 
tween patients who did and patients who did not switch (data not shown). Patients who switched were significantly younger than non-switchers ( 52.3 vs 56.8 years, $p<0.0001)$.

\section{PERITONITIS RATE AND PERITONITIS-FREE SURVIVAL}

For 899 of the 1162 patients included in the analysis (77\%), no peritonitis episode was reported. Of the remaining patients, $19 \%$ of Balance patients and $17.4 \%$ of stay - safe patients suffered a single episode of peritonitis, and 3.3\% (Balance) and 5.6\% (stay - safe) suffered two or more episodes $\left(\chi^{2}=6.22, p=0.183\right)$. Patients treated with Balance experienced 161 episodes of peritonitis yielding 7793 months of exposure (1 episode/48 months), which was identical to the rate for stay safe patients (164 episodes for 7875 months: 1 episode/48 months). There was no difference for the time to first episode of peritonitis, compared using the Kaplan-Meier method and log rank statistic ( $p=0.614$; Figure 1$)$.

\section{TECHNIQUE SURVIVAL}

According to the definition of technique survival (see Methods), 52 patients in the Balance group and 50 patients in the stay safe group experienced a technique failure. The causes for technique failure were change to competitor product, 23 (stay - safe $2 \%$, Balance $2 \%$ ); conversion to hemodialysis, 75 (stay $\cdot$ safe $6.9 \%$, Balance $6.1 \%$ ); and other, 4 (stay safe $0.2 \%$, Balance $0.5 \%$ ). None of these differences was statistically significant.

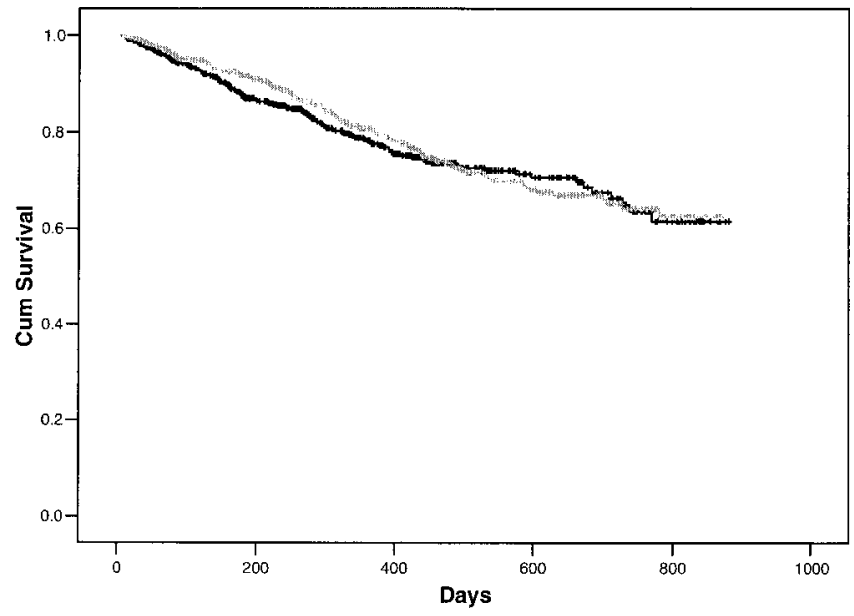

Figure 1 - Kaplan-Meier survival plot of interval to first episode of peritonitis (Balance: black line; stay - safe: gray line; both manufactured by Fresenius Medical Care, St. Wendel, Germany). There was no significant difference in peritonitisfree survival comparing the two peritoneal dialysis fluids (log rank $=0.25, p$ value $=0.614$ )
Censored events included 199 deaths (stay · safe $21.8 \%$, Balance $12.9 \%$ ), 40 renal transplants (stay safe $4 \%$, Balance $2.9 \%$ ), and 11 patients who recovered renal function (stay - safe $1.5 \%$, Balance $0.5 \%$ ). As shown in Figure 2, there was no significant difference in time to technique failure between the groups. Excluding conversions to competitor products did not significantly alter the results of the analysis (data not shown).

\section{PATIENT SURVIVAL}

In the ITT analysis, 79 patients treated with Balance and 120 treated with stay - safe died. The respective mortality rates were 12.2 deaths per 100 patient-years for Balance and 18.3 deaths per 100 patient-years for stay · safe $(p<0.004)$. The proportions of deaths caused by cardiovascular disease and infection were similar for patients treated with either PDF (data not shown). The Kaplan-Meier plot for patient survival is shown in Figure 3. At 28 months, cumulative survival for patients treated with Balance was $74 \%$ and $62 \%$ for stay - safe ( $p=$ 0.0032 ). The results of the Kaplan-Meier analyses of patient survival differed when stratification was undertaken. The superior survival identified for Balance failed to reach statistical significance when patients were stratified by age ( $\leq 60$ years, $p=0.158 ;>60$ years, $p=$ $0.106)$ and, whereas the effect of Balance was highly significant for male patients $(p=0.018)$, the effect failed to reach significance for female patients $(p=0.067)$. The survival advantage for Balance was significant for nondiabetic patients $(p=0.039)$ but fell just short of significance for diabetics $(p=0.059)$.

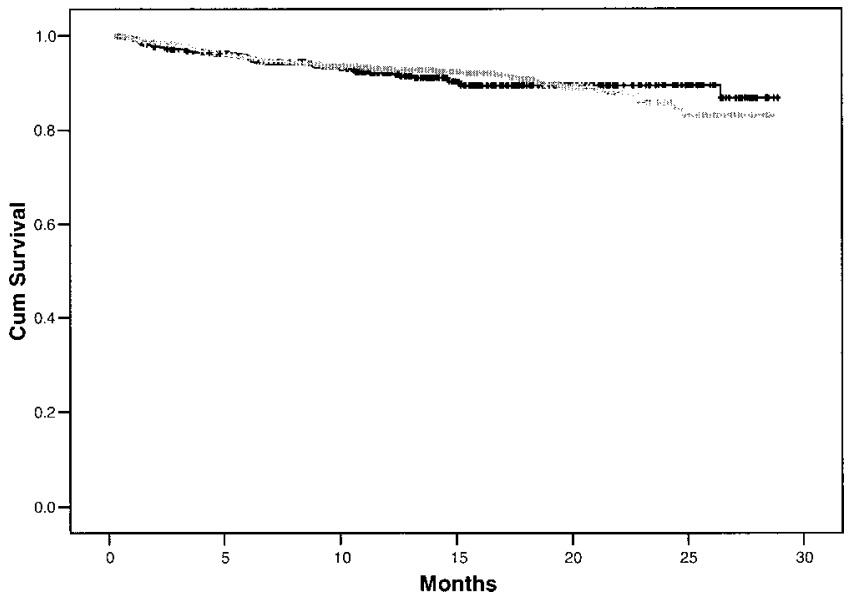

Figure 2-Kaplan-Meier plots for modality technique survival (Balance: black line; stay · safe: gray line; both manufactured by Fresenius Medical Care, St. Wendel, Germany). There was no overall difference in technique survival comparing Balance and stay . safe $(\log$ rank $=0.01, p=0.932)$. 


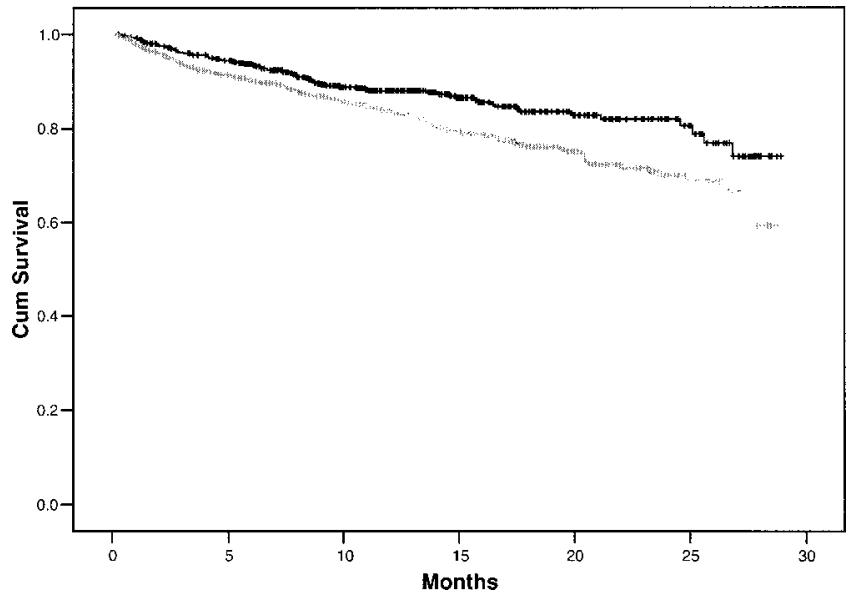

Figure 3 - Kaplan-Meier plot of patient survival (Balance: black line; stay - safe: gray line; both manufactured by Fresenius Medical Care, St. Wendel, Germany). The survival of Balance patients was significantly greater than that of stay · safe patients $(\log r a n k=8.71, p=0.0032)$.

The following covariates were entered into a Cox proportional hazard regression model: age, sex, diabetic status, and PDF used at initiation of treatment. The results of the univariate and multivariate analyses are presented in Table 3. In the univariate analysis, age and diabetes were associated with significantly increased relative risk (RR) of patient death, and treatment with Balance with a reduced RR; a statistically insignificant increased risk of death was identified for female sex. In the multivariate model, each additional year of age increased the RR of death by $6.8 \%(p<0.0001)$, and diabetes was associated with a $57 \%$ increased RR of death $(p=0.003)$. Treatment with Balance PDF independently lowered the RR of death by $25 \%(p=0.046)$.

\section{DISCUSSION}

The most remarkable finding from this retrospective study involving over 1100 incident Korean patients treated by CAPD for up to 30 months is the superior survival of patients treated with the PDF with lower concentration of GDPs and neutral pH (Balance), compared to patients treated with a conventional PDF. Despite a marginally significant difference in patient age (stay - safe older than Balance, $p=0.049$ ) and a higher proportion of diabetics in the stay - safe group (not significant; $p=0.685$ ), the use of Balance remained an independent predictor of reduced RR of death in the multivariate Cox proportional hazards model, which included patient sex, age, and diabetic status. No differences between the two PDFs were identified for technique (modality) survival or for peritonitis-free survival or peritonitis rates.

The analysis by ITT, if anything, tended to favor patients allocated to the stay-safe group. Patients who switched from stay safe to Balance were considerably younger (by 4.5 years, $p<0.0001$ ) than patients who did not switch and there were marginally fewer diabetic patients ( $50 \%$ vs $53 \%$; not significant). As expected, this group of patients had a significantly lower mortality rate (7.8/100 patient-years) compared to patients treated by either PDF and who did not switch (stay-safe 27.4 and Balance 12.2 deaths/100 years). In a multivariate Cox proportional hazards regression analysis using a per protocol (as treated) allocation to PDF and including age, sex, and diabetic status as covariates, treatment with Balance was independently associated with a $55 \%$ reduction in RR of death ( $p<0.0001$; data not shown).

Unfortunately, the analysis is limited by the absence of data about factors known to affect the survival of CAPD patients, including RRF, dialysis adequacy, and peritoneal transport status. Furthermore, the lack of data that would define the prescribing physicians' reasons for prescribing one or other PDF or for switching patients from the conventional PDF to Balance necessarily raises questions of ascertainment bias (positive selection for the Balance PDF). We believe it unlikely that one or more of

TABLE 3

Results of the Univariate and Multivariate Cox Regression Analysis of Predictors of Patient Death Based on Intention-to-Treat Allocation to Peritoneal Dialysis Fluid (PDF)

\begin{tabular}{|c|c|c|c|c|c|c|c|c|}
\hline & \multicolumn{4}{|c|}{$\begin{array}{l}\text { Univariate model } \\
95 \% \text { confidence interval }\end{array}$} & \multicolumn{4}{|c|}{$\begin{array}{c}\text { Multivariate model } \\
95 \% \text { confidence interval }\end{array}$} \\
\hline & $\mathrm{RR}$ & Lower & Upper & $p$ Value & $\mathrm{RR}$ & Lower & Upper & $p$ Value \\
\hline Female (vs male) & 1.132 & 0.857 & 1.495 & 0.382 & 1.274 & 0.963 & 1.685 & 0.090 \\
\hline Diabetic (vs nondiabetic) & 2.042 & 1.515 & 2.753 & 0.000 & 1.569 & 1.163 & 2.117 & 0.003 \\
\hline Age (each year older) & 1.071 & 1.057 & 1.085 & 0.000 & 1.068 & 1.055 & 1.082 & 0.000 \\
\hline PDF (Balance ${ }^{\mathrm{a}}$ vs stay $\cdot$ safe $\left.^{\mathrm{a}}\right)$ & 0.654 & 0.492 & 0.869 & 0.003 & 0.748 & 0.562 & 0.995 & 0.046 \\
\hline
\end{tabular}

a Manufactured by Fresenius Medical Care, St. Wendel, Germany. 
these factors with known relevance to patient survival could be so differently distributed in the two treatment groups as to explain the observed survival difference. We recognize the possibility that physicians might select patients with an overall better prognosis when prescribing a novel treatment that promises a benefit such as prolonged technique survival. The lower age of the patients selected to be treated with Balance would be consistent with such bias, but we think it unlikely that such bias would fully explain the survival advantage for the patients treated with Balance. Furthermore, the patients analyzed by ITT as stay - safe patients included 175 patients who were converted to Balance. This group of patients was significantly younger (and presumably at lower risk) than the patient group treated exclusively with Balance and would "bias" the results in favor of the stay - safe group. The similar rates of peritonitis and the identical technique survival rates experienced by patients treated with either PDF also argue against such a bias. The only means of resolving these and related issues is through an adequately powered, randomized, controlled clinical trial.

Might the difference in outcomes be somehow related to a "center" effect? Because of the distribution of patients across the 83 centers (see Methods), it was not possible to examine for a center effect in the full Cox proportional hazards model. We identified 9 centers that each contributed in excess of 30 patients and treated patients with both PD solutions (stay · safe 210, Balance 256). In a separate analysis of those patients, stay - safe patients were significantly older ( 56 vs 53 years, $p=0.037$ ) and had a slight but insignificant excess of diabetics $(49.5 \%$ vs $47.3 \%, p=0.257)$. In this subset analysis, comparative gross mortality was $17 \%$ for patients treated with stay - safe and $7.8 \%$ for patients treated with the Balance solution. In a Kaplan-Meier analysis, a survival advantage for Balance patients at 28 months failed to reach statistical significance (log rank $=3.42, p=0.0645)$. In a Cox regression analysis, age [RR of death for each additional year 1.05, 95\% confidence interval (CI) 1.025 1.076] and diabetes (RR of death 1.94 vs nondiabetic, $95 \%$ CI $1.113-3.466$ ) were associated with mortality but no significant impact for the PD solution and no center effect were identified. This negative result of the effect of the PD solution on survival must be viewed with caution (type II error) in light of the reduced number of patients and mortal events included in the analysis.

Another possible criticism relates to whether these results can reasonably be extrapolated to other populations of PD patients. The Korean patient population described here is ethnically and racially homogenous. Over recent years, Korean PD clinicians have extensively reported their outcomes for PD in the Korean and international medical literature (20-22). Overall, these publications do not suggest that Korean patients treated with PD differ in any essential respect from their counterparts treated elsewhere. However, the hypothesis suggested by these results in Korean patients - that the use of more biocompatible PDF results in superior patient outcome - needs to be tested in patients of other racial and ethnic mixes.

Any discussion of what mechanism or mechanisms might explain superior patient survival for a PDF with low GDP concentration and neutral $\mathrm{pH}$ is necessarily conjectural. A large amount of literature addresses experimental data related to PD solutions with the chemical characteristics of Balance. Peritoneal dialysis solutions with low GDP concentration and neutral $\mathrm{pH}$ have been identified as generally less cytotoxic for mesothelial cells $(16,17)$ and resident host-defense cells $(14,15,23)$. Several clinical studies have reported an increase in cancer antigen 125 levels in peritoneal effluent with these solutions compared to standard PDF $(18,24,25)$. The inference is that low-GDP solutions preserve mesothelial cell mass or cell vitality. As of now, there is no evidence that preservation of mesothelial cell mass or homeostasis protects patients from adverse outcomes. Peritoneal dialysis fluids with low GDP content and neutral $\mathrm{pH}$ have also been shown to be associated with superior function of peritoneal host-defense cells, including resident macrophages and polymorphonuclear leukocytes (23). The promise of such data is that rates of peritonitis or the course of episodes of peritonitis would be favorably impacted by the use of low-GDP solutions. Montenegro et al. recently presented their preliminary report of lower peritonitis rates with neutral $\mathrm{pH}$, low GDP, bicarbonate solutions (26). In the present study, we failed to observe any difference in the rate of peritonitis.

Numerous studies, including CANUSA, have demonstrated that survival of $P D$ patients is highly correlated with RRF (27-29). In the Euro Balance Trial, patients treated with low-GDP PD solution exhibited a trend toward better preservation of RRF (18). In the same study, patients treated with Balance, the low-GDP solution, were found to have lower serum concentrations of advanced glycation end-product (AGE) markers (carboxymethyllysine and imidazolone) than when treated with standard solution, although the authors found no correlation between AGE markers and RRF (18). AGEs have been extensively implicated in microvascular and macrovascular disease in uremic and diabetic patients, and GDPs and AGEs have been implicated in contributing to local and systemic microinflammation $(30,31)$. Directly, or indirectly through lesser induction of inflammation, a reduction in advanced glycation might result in preservation of RRF. 
Several clinical studies have reported a reduction in the concentration of peritoneal effluent hyaluronan when patients are converted from conventional PDF to low-GDP PDF $(18,24)$, with the inference that local peritoneal inflammation is reduced by these solutions. As of now, there are no reports that use of low-GDP solutions is associated with reduction in levels of markers of systemic inflammation. Like their hemodialysis counterparts, PD patients exhibit a chronically inflamed state, as evidenced by elevated serum concentration of proinflammatory cytokines and C-reactive protein (32-34). Extensive epidemiological evidence both in the general population (35) and in uremic and dialysis patients associates chronic microinflammation with mortality, as reviewed by Arici and Walls (36). In a recent publication, the finding of an elevated C-reactive protein concentration predicted outcome in PD patients (37). Moreover, a state of chronic inflammation is associated with accelerated decline in RRF (33). In the present study, we lack data allowing the measurement of inflammatory status, and RRF was not monitored. In any future prospective study seeking to examine the effect of novel low-GDP solutions on patient outcome, inflammatory markers and RRF should be monitored and we are aware of a proposed randomized controlled trial to be initiated soon in Australia and New Zealand (the balANZ Trial) that will examine these variables.

In conclusion, from this study we observe a superior survival of patients treated with a PD solution with low GDP content and neutral pH. As an observational study, it has many limitations, as discussed above. However, the magnitude of the result, the superior patient survival experienced by patients treated with the biocompatible PDF, should prompt the undertaking of appropriately designed, prospective, randomized controlled studies seeking to affirm the observational results reported here.

\section{ACKNOWLEDGMENTS}

The authors express their appreciation to the physicians and nurses of the centers that contributed patients and data for this analysis. We also gratefully acknowledge Dr. H.F. Woods (Fresenius Medical Care, Asia Pacific) for his comments and help in the statistical analysis and preparation of the manuscript.

\section{REFERENCES}

1. Ganter G. Ueber die Beseitigung giftiger Stoffe aus dem Blute durch Dialyse. Munch Med Wochschr 1923; 70:1478.

2. Davies SJ, Bryan J, Phillips L, Russell GI. Longitudinal changes in peritoneal kinetics: the effects of peritoneal dialysis and peritonitis. Nephrol Dial Transplant 1996; 11:498.

3. Williams JD, Craig KJ, Topley N, Von Ruhland C, Fallon M, Newman GR, et al. Morphologic changes in the peritoneal membrane of patients with renal disease. J Am Soc Nephrol 2002; 13:470-9.

4. Nakayama M, Kawaguchi Y, Yamada K, Hasegawa T, Takazoe $\mathrm{K}$, Katoh $\mathrm{N}$, et al. Immunohistochemical detection of advanced glycosylation end-products in the peritoneum and its possible pathophysiological role in CAPD. Kidney Int 1997; 51:182-6.

5. Honda K, Nitta K, Horita S, Yumura W, Nihei H, Nagai R, et al. Accumulation of advanced glycation end products in the peritoneal vasculature of continuous ambulatory peritoneal dialysis patients with low ultra-filtration. Nephrol Dial Transplant 1999; 14:1541-9.

6. Paniagua R, Amato D, Vonesh E, Correa-Rotter R, Ramos $A$, Moran J, et al. Effects of increased peritoneal clearances on mortality rates in peritoneal dialysis: ADEMEX, a prospective, randomized controlled trial. J Am Soc Nephrol 2002; 13:1307-20.

7. Piraino B. How much peritoneal dialysis is needed for optimal outcomes? Semin Dial 2003; 16:367-9.

8. Stenvinkel P. Interactions between inflammation, oxidative stress and endothelial dysfunction in end-stage renal disease. J Ren Nutr 2003; 13:144-8.

9. Witowski J, Bender T0, Wisniewska-Elnur J, Ksiazek K, Passlick-Deetjen J, Breborowicz A, et al. Mesothelial toxicity of peritoneal dialysis fluids is related primarily to glucose degradation products, not to glucose perse. Perit Dial Int 2003; 23:381-90.

10. Wieslander AP, Deppisch R, Svensson E, Forsbäck G, Speidel R, Rippe B. In vitro biocompatibility of a heat-sterilized, low-toxic, and less acidic fluid for peritoneal dialysis. Perit Dial Int 1995; 15:158-64.

11. Alscher DM, Pauli-Magnus C, Kirchgessner J, Kuhlmann U, Mettang T. A new lactate-based, plasticizer-free, neutral peritoneal dialysis fluid provided in a two-compartment system: effect on peripheral leukocyte function. Nephron 2000; 86:62-9.

12. Mortier S, De Vriese AS, Van de Voorde J, Schaub TP, Passlick-Deetjen J, Lameire NH. Hemodynamic effects of peritoneal dialysis solutions on the rat peritoneal membrane: role of acidity, buffer choice, glucose concentration, and glucose degradation products [Erratum published in J Am Soc Nephrol 2002; 13(5):1419-22]. J Am Soc Nephrol 2002; 13:480-9.

13. Douvdevani A, Rapoport J, Konforty A, Yulzari R, Moran A, Chamovitz C. Intracellular acidification mediates the inhibitory effect of peritoneal dialysate on peritoneal macrophages. J Am Soc Nephrol 1995; 6:207-13.

14. Liberek T, Topley N, Jorres A. Peritoneal dialysis fluid inhibition of polymorphonuclear leukocyte respiratory burst activation is related to the lowering of intracellular $\mathrm{pH}$. Nephron 1993; 65:260-5. 
15. Liberek T, Topley N, Jörres A, Coles GA, Gahl GM, Williams JD. Peritoneal dialysis fluid inhibition of phagocyte function: effects of osmolality and glucose concentration. J Am Soc Nephrol 1993; 3:1508-15.

16. Witowski J, Korybalska K, Ksiazek K, Wisniewska-Elnur J, Jorres A, Lage $\mathrm{C}$, et al. Peritoneal dialysis with solutions low in glucose degradation products is associated with improved biocompatibility profile towards peritoneal mesothelial cells. Nephrol Dial Transplant 2004; 19:917-24.

17. Wieczorowska-Tobis K, Brelinska R, Witowski J, PasslickDeetjen J, Schaub TP, Schilling $H$, et al. Evidence for less irritation to the peritoneal membrane in rats dialyzed with solutions low in glucose degradation products. Perit Dial Int 2004; 24:48-57.

18. Williams JD, Topley N, Craig KJ, Mackenzie RK, Pischetsrider M, Lage C, et al. The Euro-Balance Trial: the effect of a new biocompatible peritoneal dialysis fluid (Balance) on the peritoneal membrane. Kidney Int 2004; 66:408-18.

19. Lambert MC, Lage C, Kirchgessner J. stay - safe. A new PVC free system in long-term CAPD treatment. EDTNA ERCA J 1999; 25:30-4.

20. Park JH, Koh SH, Kim BS, Yang CW, Kim YS, Kim SY, et al. Reference range of values of peritoneal equilibration test and changes in peritoneal kinetics in Korea long-term CAPD patients. Korean J Nephrol 1998; 17:945-51.

21. Kang DH, Toon KI, Choi KB, Lee R, Lee HY, Han DS, et al. Relationship of peritoneal membrane transport characteristics to the nutritional status in CAPD patients. Nephrol Dial Transplant 1999; 14:1715-22.

22. Roh HJ, Ryu DR, Yoo TH, Park HC, Shin SK, Kang SW, et al. Predictors and clinical features of long-term continuous ambulatory peritoneal dialysis (CAPD). Korean J Nephrol $2001 ; 20: 306-14$.

23. Mortier S, De Vriese AS, McLoughlin RM, Topley N, Schaub TP, Passlick-Deetjen J, et al. Effects of conventional and new peritoneal dialysis fluids on leukocyte recruitment in the rat peritoneal membrane. J Am Soc Nephrol 2003; 14:1296-306.

24. Rippe B, Simonsen 0, Heimburger 0, Christensson A, Haraldsson B, Stelin G, et al. Long-term clinical effects of a peritoneal dialysis fluid with less glucose degradation products. Kidney Int 2001; 59:348-57.

25. Jones S, Holmes CJ, Krediet RT, Mackenzie R, Faict D, Tranaeus A, et al. Bicarbonate/lactate-based peritoneal dialysis solution increases cancer antigen 125 and decreases hyaluronic acid levels. Kidney Int 2001; 59: 1529-38.

26. Montenegro J, Munoz RI, Martinez I, Ocharan J, Saracho
$\mathrm{R}$, Valladares $\mathrm{E}$. Important decrease of peritonitis incidence using new double-chamber bicarbonate solution in CAPD [Abstract]. J Am Soc Nephrol 2003; 14:480A.

27. Jager KJ, Merkus MP, Dekker FW, Boeschoten EW, Tijssen $\mathrm{JG}$, Stevens P, et al. Mortality and technique failure in patients starting chronic peritoneal dialysis: results of The Netherlands Cooperative Study on the Adequacy of Dialysis. NECOSAD Study Group. Kidney Int 1999; 55:1476-85.

28. Bargman JM, Thorpe KE, Churchill DN, for the Canada-USA (CANUSA) Peritoneal Dialysis Group. The relative contribution of residual renal function and peritoneal clearance to adequacy of dialysis: a re-analysis of the Canada-USA (CANUSA) Study. J Am Soc Nephrol 2001; 12:2158-62.

29. Termorshuizen F, Korevaar JC, Dekker FW, van Manen JG, Boeschoten EW, Krediet R. The relative importance of residual renal function compared with peritoneal clearance for patient survival and quality of life: an analysis of the Netherlands Cooperative Study on the Adequacy of Dialysis (NECOSAD)-2. Am J Kidney Dis 2003; 41:1293-302.

30. Lieuw A, Fa ML, van Hinsbergh VW, Teerlink T, Barto R, Twisk J, et al. Increased levels of N(epsilon)-(carboxymethyl)lysine and $\mathrm{N}$ (epsilon)-(carboxyethyl)-lysine in type 1 diabetics with impaired renal function: correlation with markers of endothelial dysfunction. Nephrol Dial Transplant 2004; 19:631-6.

31. Peppa M, Uribarri J, Cai W, Lu M, Vlassara H. Glycoxidation and inflammation in renal failure patients. Am J Kidney Dis 2004; 43:690-5.

32. Chung SH, Heimburger 0 , Lindholm B, Stenvinkel P. Chronic inflammation in PD patients. Contrib Nephrol 2003; 140:104-11.

33. Chung SH, Heimburger 0, Stenvinkel P, Qureshi AR, Lindholm B. Association between residual renal function, inflammation and patient survival in new peritoneal dialysis patients. Nephrol Dial Transplant 2003; 18:590-7.

34. Chung SH, Heimburger 0 , Lindholm B, Stenvinkel P. Chronic inflammation in PD patients. Contrib Nephrol 2003; 140:104-11.

35. Ridker PM, Cushman M, Stampfer MJ, Tracy RP, Heenekens $\mathrm{CH}$. Inflammation, aspirin and the risk of cardiovascular disease in apparently healthy men. N Engl J Med 1997; 336:973-9.

36. Arici M, Walls J. End stage renal disease, atherosclerosis and cardiovascular mortality: is C-reactive protein the missing link? Kidney Int 2001; 59:407-14.

37. Herzig KA, Purdie DM, Chang W, Brown AM, Hawley CM, Campbell SB, et al. Is C-reactive protein a useful predictor of outcomes in peritoneal dialysis patients. J Am Soc Nephrol 2001; 12:814-21. 